\title{
Brazilian Psychiatric Association guidelines for the management of suicidal behavior. Part 1. Risk factors, protective factors, and assessment
}

Leonardo Baldaçara, ${ }^{1,2}$ iD Gislene A. Rocha, ${ }^{2,3,4}$ iD Verônica da S. Leite, ${ }^{1,2,5}$ iD Deisy M. Porto, ${ }^{2,6}$ iD Roberta R. Grudtner, ${ }^{2,7,8}$ iD Alexandre P. Diaz, ${ }^{2,9,10}$ iD Alexandrina Meleiro, ${ }^{2}$ (iD Humberto Correa, ${ }^{2,11}$ (iD Teng C. Tung, ${ }^{2,12,13}$ (iD) João Quevedo, ${ }^{2,9,10}$ (iD Antônio G. da Silva ${ }^{2,14}$ (iD)

${ }^{1}$ Universidade Federal do Tocantins, Palmas, TO, Brazil. ${ }^{2}$ Associação Brasileira de Psiquiatria (ABP), Rio de Janeiro, RJ, Brazil. ${ }^{3}$ Hospital Universitário Clemente de Faria, Universidade Estadual de Montes Claros, Montes Claros, MG, Brazil. ${ }^{4}$ Serviço Especializado em Reabilitação em Deficiência Intelectual, Associação de Pais e Amigos dos Excepcionais, Montes Claros, MG, Brazil. ${ }^{5}$ Secretaria Municipal de Saúde de Palmas, Palmas, TO, Brazil. ${ }^{6}$ Associação Catarinense de Psiquiatria, Florianópolis, SC, Brazil. ${ }^{7}$ Núcleo de Dor e Neuromodulação, Universidade Federal do Rio Grande do Sul (UFRGS), Porto Alegre, RS, Brazil. ${ }^{8}$ Secretaria Estadual da Saúde, Porto Alegre, RS, Brazil. ${ }^{9}$ Translational Psychiatry Program, Faillace Department of Psychiatry and Behavioral Sciences, McGovern Medical School, The University of Texas Health Science Center at Houston, Houston, TX, USA. ${ }^{10}$ Laboratório de Psiquiatria Translacional, Programa de Pós-Graduação em Ciências da Saúde, Universidade do Extremo Sul Catarinense (UNESC), Criciúma, SC, Brazil. ${ }^{11}$ Universidade Federal de Minas Gerais (UFMG), Belo Horizonte, MG, Brazil. ${ }^{12}$ Instituto de Psiquiatria (IPq), Hospital das Clínicas, Faculdade de Medicina, Universidade de São Paulo (HCFMUSP), São Paulo, SP, Brazil. ${ }^{13}$ Serviços de Pronto Socorro e Interconsultas, IPq, HCFMUSP, São Paulo, SP, Brazil. ${ }^{14}$ Asociación Psiquiátrica de América Latina (APAL).

\begin{abstract}
Suicide is a global public health problem that causes the loss of more than 800,000 lives each year, principally among young people. In Brazil, the average mortality rate attributable to suicide is approximately 5.23 per 100,000 population. Although many guidelines have been published for the management of suicidal behavior, to date, there are no recent guidelines based on the principles of evidence-based medicine that apply to the reality of suicide in Brazil. The objective of this work is to provide key guidelines for managing patients with suicidal behavior in Brazil. This project involved 11 Brazilian psychiatry professionals selected by the Psychiatric Emergencies Committee (Comissão de Emergências Psiquiátricas) of the Brazilian Psychiatric Association for their experience and knowledge in psychiatry and psychiatric emergencies. For the development of these guidelines, 79 articles were reviewed (from 5,362 initially collected and 755 abstracts). In this review, we present definitions, risk and protective factors, assessments, and an introduction to the Safety Plan. Systematic review registry number: CRD42020206517
\end{abstract}

Keywords: Suicide; completed suicide; suicide attempt; mental disorders; guideline

\section{Introduction}

Psychiatric emergencies are changes in behavior that place the patient or others at risk and require immediate therapeutic intervention (within minutes or a few hours) to avoid harmful progression. Among them are suicidal behavior, mood episodes, self-mutilation, severely impaired judgment, severe self-neglect, intoxication or abstinence, and aggressive psychomotor agitation. ${ }^{1-5}$ According to the World Health Organization (WHO), suicide is a serious public health problem and one of the leading causes of death worldwide. ${ }^{6-8}$ Throughout the world, approximately 800,000 people die by suicide each year, accounting for $1.5 \%$ of all deaths. ${ }^{9}$ Suicide is the

Correspondence: Leonardo Baldaçara, Quadra 401 Sul, Avenida Joaquim Teotônio Segurado, 1, Espaço Médico, sala 1006, CEP 77015-550, Palmas, TO, Brazil.

E-mail: leonardobaldassara@ gmail.com

Submitted Apr 03 2020, accepted Jun 21 2020, Epub Oct 232020. 10th leading cause of death in North America and the foremost cause of death worldwide among persons 15 to 24 years of age. ${ }^{10,11}$

The WHO estimated that the 2016 suicide rate was 10.6 per 100,000 persons, with $80 \%$ of suicides occurring in low- and middle-income countries. ${ }^{6,8,10,11}$ Across the six WHO regions, the incidence of suicide differed by a factor of four between the region with the highest rate (Europe) and the region with the lowest rate (the Eastern Mediterranean, including the Middle East). Worldwide, suicide rates are higher in older people and among men (15.6 suicides per 100,000 ) than they are among women $(7.0$ per 100,000$){ }^{6,11}$ In addition, suicide rates have been declining over time in most of these regions, and some
How to cite this article: Baldaçara L, Rocha GA, Leite VS, Porto DM, Grudtner RR, Díaz AP, et al. Brazilian Psychiatric Association guidelines for the management of suicidal behavior. Part 1. Risk factors, protective factors, and assessment. Braz J Psychiatry. 2021;43:525-537. http://dx.doi.org/10.1590/1516-4446-2020-0994 
places did not reach the WHO estimate in 2020. Of total deaths by suicide, $84.7 \%$ occurred among 15 -to-59-yearolds. ${ }^{6}$ Suicide also has profound implications for families and communities, and incurs massive societal costs estimated at over 93 billion dollars per year in the United States alone. ${ }^{12}$

In Brazil, 50,664 deaths from suicide were registered from 2010 to 2014, and the average suicide mortality rate was 5.23 per 100,000 population. ${ }^{13}$ The Brazilian municipalities with the highest rates were Taipas do Tocantins, state of Tocantins (79.68 deaths per 100,000 population); Itaporã, state of Mato Grosso do Sul (75.15 deaths per 100,000); Mampituba, state of Rio Grande do Sul (52.98 deaths per 100,000 population); Paranhos, state of Mato Grosso do Sul (52.41 deaths per 100,000); and Monjolos, state of Minas Gerais (52.08 deaths per 100,000). ${ }^{13}$

Although many guidelines have been published for the management of suicidal behavior, to date, there are no recent guidelines based on the principles of evidencebased medicine that apply to the reality of suicide in Brazil.

The objective of this study is to provide key guidelines for managing patients with suicidal behavior in Brazil.

\section{Methods}

This project involved 11 Brazilian psychiatry professionals selected by the Psychiatric Emergencies Committee (Comissão de Emergências Psiquiátricas) of the Brazilian Psychiatric Association for their experience and knowledge in psychiatry and psychiatric emergencies. For the development of these guidelines, the MEDLINE (via PubMed), Cochrane Database of Systematic Reviews, Web of Science, and SciELO databases were searched for articles published from 1997 to 2020 in English or Portuguese. The search strategy used was based on questions structured according to the PICO format ("patient or population," "intervention or exposure," "control or comparison," and "outcome"), as recommended by the Guidelines Project of the Brazilian Medical Association (AMB). The use of structured clinical questions aimed at facilitating the elaboration of strategies to search for evidence. The descriptors used were "suicide" OR "suicidal behavior" AND "risk factors" OR "protective factors" OR "assessment." Systematic reviews with metaanalysis were prioritized, and other types of research were only sought when the information was not found.

In evaluating the literature, despite a large number of clinical trials and reviews, some difficulties were found in evaluating the results: the evaluation of suicidal behavior in several different diagnoses, evaluation and follow-up of suicidal behavior in different settings, and evaluation of interventions in a small number of patients, with different instruments and outcome criteria. Therefore, the following criteria were standardized: 1) studies on suicidal behavior for adults (18 to 65 years); and 2) objective assessment of response, either by reduction of symptoms or by an objective scale. The exclusion criteria were as follows: 1) studies with fewer than 20 participants in the sample; 2) incomplete data and low-quality statistical analysis.

In addition, articles deemed to be relevant to the literature were also used in the development of the guidelines.
The article selection process proceeded as follows: i) selection of the relevant article summaries; ii) reading the relevant articles in full; iii) critical analysis of evidence; and iv) extraction of results and classification of evidence strength. Levels of evidence and grades of recommendations were selected according to the Oxford classification 2011. For more details, see https://www.cebm.net/wpcontent/uploads/2014/06/CEBM-Levels-of-Evidence-2.1. pdf. In the text, we will present our recommendation grades, and in the descriptive table of the selected articles, we will present the levels of evidence. Of 5,362 entries initially retrieved and 755 abstracts on the drug approach, 79 articles were ultimately reviewed (Figure 1). Tables S1 and S2, available as online-only supplementary material, present details as well as the level of evidence of the selected articles.

\section{Definitions}

Definitions of suicidal behavior are highly variable, imprecise, and often changing, especially in regard to nonfatal suicidal behavior and suicidal ideation. Suicidality covers suicidal ideation (serious thoughts about taking one's own life), suicide plans, and suicide attempts. However, Meyer et al. ${ }^{14}$ proposed abandoning this term. This author suggests using suicide ideation, suicidal behavior, and suicide as the preferred terms.

In this guideline, we will standardize the terms as described in Box 1.

\section{Risk factors}

Risk factors for suicide have been investigated at the population and individual levels; in addition, predisposing factors and precipitating events have been examined, mainly at the individual level. Each of these factors can be mediated through genetic, psychological, and personality characteristics, making most explanatory models complex and difficult to interpret. ${ }^{10}$

Patients seeking care for suicidal behavior should undergo risk factor assessment to identify those who need intensive supervision and who should receive more clinical resources. ${ }^{16-19}$ Some authors propose that risk factors cannot be defined and identified in an isolated and precise manner, and that fatalities occur due to the sum of multiple variables. ${ }^{16}$ There is still little statistically robust evidence to justify the isolated use of these risk factors; therefore, in future, cohort studies using multivariable methodology should elucidate whether variables independently associated with suicide exist. ${ }^{16}$ Psychiatrists and other physicians must be careful not to reduce patient assessment to a search for specific information, and instead combine the patient's history with risk factors, protection, access to healthcare sources, motivations, and psychosocial support networks. ${ }^{19}$

The literature suggests an association between alleged high-risk factors and completed suicide. ${ }^{16,18-21}$ However, a meta-analysis found that approximately half of all suicides are likely to occur in low-risk groups, and that $95 \%$ of high-risk patients do not commit suicide. Therefore, these findings must be interpreted with caution. ${ }^{16}$ 


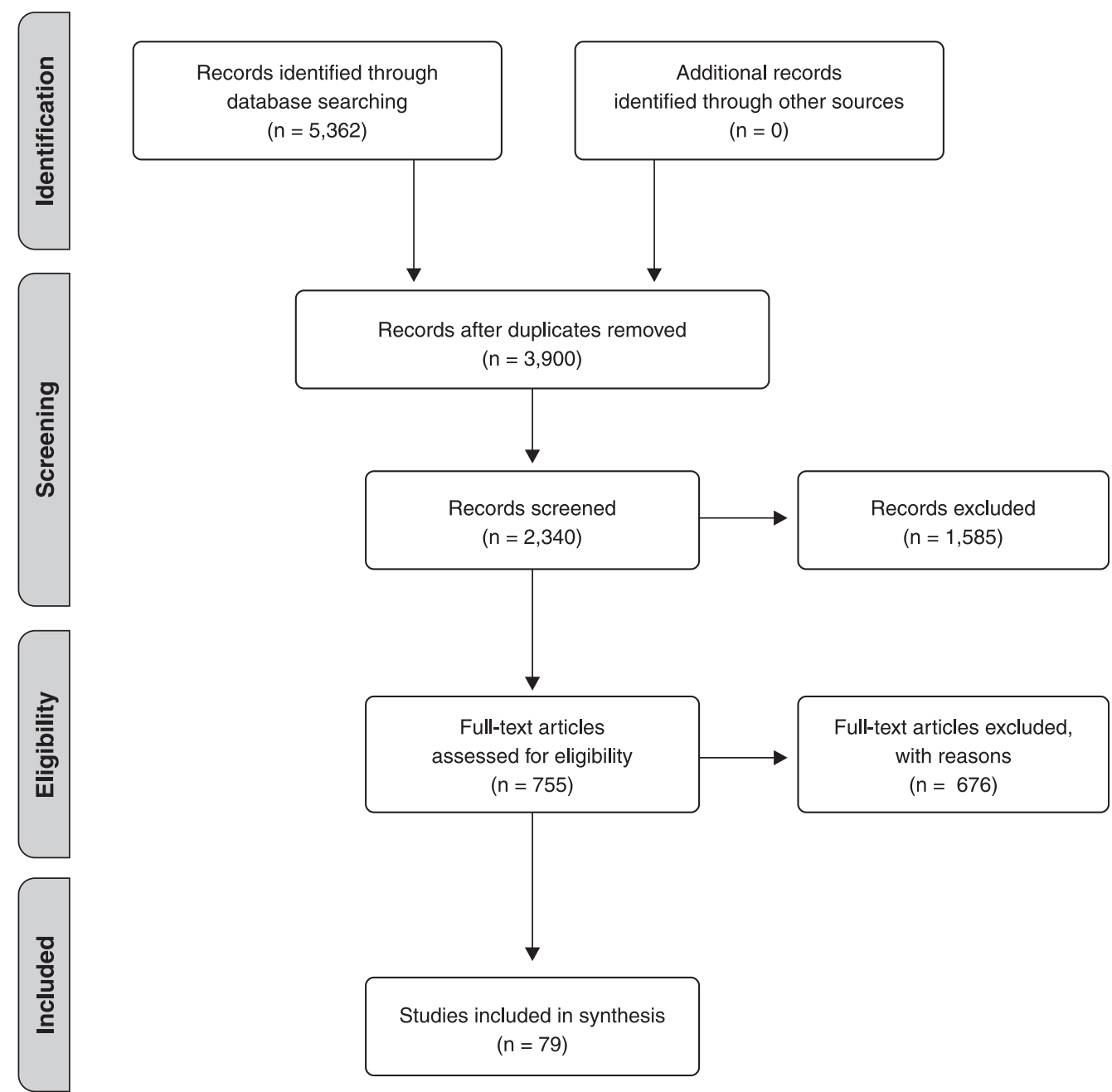

Figure 1 PRISMA flowchart for the study selection process.

Box 1 Main suicidal behavior terms suggested ${ }^{15}$

Completed suicide

Preparatory acts toward imminent suicidal behavior (or suicide plan)

Suicide attempt

Suicidal ideation
A self-injurious behavior that resulted in fatality and was associated with at least some intent to die as a result of the act.

The individual takes steps to injure him- or herself, but is stopped by self or others from starting the self-injurious act before the potential for harm has begun.

A potentially self-injurious behavior, associated with at least some intent to die because of the act. Evidence that the individual intended to kill him- or herself, at least to some degree, can be explicit or inferred from the behavior or circumstance. A suicide attempt may or may not result in actual injury.

Passive thoughts about wanting to be dead or active thoughts about killing oneself, not accompanied by preparatory behavior.
In another study, no factor or combination of factors was strongly associated with suicide in the year after discharge among patients who were hospitalized for suicidal behavior. Approximately $3 \%$ of patients categorized as being at high risk can be expected to commit suicide in the year after discharge, while approximately $60 \%$ of the patients who commit suicide are likely to be categorized as low risk. ${ }^{22}$
It is important to point out that there are no universal risk factors, and that each of those observed in research were only detected after comparison to different variables. Tables 1 and 2 show the main risk factors identified to date. However, we emphasize that no single factor is predictive of attempted or completed suicide. Generally, the sum of several factors, in addition to symptomatic disease, is the trigger for the event. We present only risk 
Table 1 Risk factors* for suicide attempt

Risk factor

Acute alcohol use 23

Affiliation and attachment ${ }^{24}$

Alcohol use $\mathrm{u}^{2,25}$

Antidepressants in pediatric MDD, OCD, and anxiety disorders ${ }^{26}$

Antidepressants in short-term use, compared to placebo ${ }^{27}$

Anxiety ${ }^{28,29,30}$

Arousal $^{24}$

$B D N F$ polymorphism Val66Met in persons with psychiatric disorders ${ }^{31}$

Bipolar disorder type $11^{32}$

Bipolar disorder with female sex, younger age of illness onset, depressive polarity, comorbid anxiety disorder, any comorbid substance use disorder, alcohol use disorder, any illicit substance use, comorbid cluster B/borderline personality

disorder, and first-degree family history of suicide

Body dysmorphic disorder

Bullying ${ }^{33}$

Child maltreatment ${ }^{30,33}$

Childhood sexual abuse $33-35$

Chronic cannabis use ${ }^{36}$

Cognitive systems (e.g., impulsiveness, attention problems) ${ }^{24}$

Community violence ${ }^{33}$

Dating violence ${ }^{33}$

Depressed mood 24,37

Depressive symptoms during first-episode psychosis $^{38}$

Derangements of central serotonergic function ${ }^{24}$

Emotional abuse 39

Exposure to self-injurious thoughts and behaviors of others (e.g., friends, family members, schoolmates, etc. $)^{40}$

Family history of self-injurious thoughts and behaviors ${ }^{40}$

Frustrative nonreward ${ }^{24}$

Higher cortisol levels below age 40 years $^{41}$

Homosexuality or bisexuality in men ${ }^{42}$

Hopelessness 24

Impaired cognitive inhibition in affective disorders ${ }^{43}$

In persons exhibiting NSSI: NSSI frequency, number of NSSI methods, and hopelessness; borderline personality disorder, impulsivity, posttraumatic stress disorder, NSSI method of cutting, and depression ${ }^{44}$

Low psychosocial functioning with childhood sexual abuse ${ }^{35}$

Lower lipid levels ${ }^{45}$

Mood disorder ${ }^{46}$

Negative attributional style ${ }^{24}$

Neuroticism ${ }^{24}$

Obesity $^{34}$

One child in family ${ }^{46}$

Perception and understanding of self ${ }^{24}$

Physical abuse ${ }^{39}$

Physical neglect ${ }^{39}$

Physical pain ${ }^{47}$

Placebo use in adolescents with MDD, OCD, and anxiety disorders ${ }^{26}$

Polygenic risk scores for major depression, bipolar disorder, and schizophrenia ${ }^{48}$

Poor relationship with family ${ }^{46}$

Previous suicide attempts ${ }^{35}$

Psychotic unipolar depression ${ }^{49}$

PTSD ${ }^{50}$

Rumination ${ }^{24}$

Schizophrenia with history of alcohol use or family history of psychiatric illness ${ }^{51}$

Schizophrenia with physical comorbidity or history of depression, family history of suicide, or history of drug use, or history of tobacco use, or being white, and depressive symptoms ${ }^{51}$

Self-injurious thoughts and behaviors ${ }^{40}$

Serotonin transporter $(5-H T T)$ gene polymorphism ${ }^{52,53}$

Sexual abuse ${ }^{39}$

Sleep disorders (insomnia, parasomnias, and sleep-related breathing disorders) associated with psychiatric disorders ${ }^{54}$

Sleep-wakefulness ${ }^{24}$

Smoking ${ }^{46,55}$

Substance use disorder ${ }^{46,56}$

Suicidal ideation and suicide plans ${ }^{40}$

Suicide of relatives ${ }^{46}$

Suicide theory-relevant risk factors ${ }^{24}$

TPH2 polymorphisms ${ }^{57}$

Unemployment ${ }^{58}$

evidence

BDNF = brain-derived neurotrophic factor; MDD = major depressive disorder; NSSI = non-suicidal self-injury; OCD = obsessive-compulsive disorder; PTSD = posttraumatic stress disorder.

* Depends on the reference group. 
Table 2 Risk factors for suicide death or completed suicide

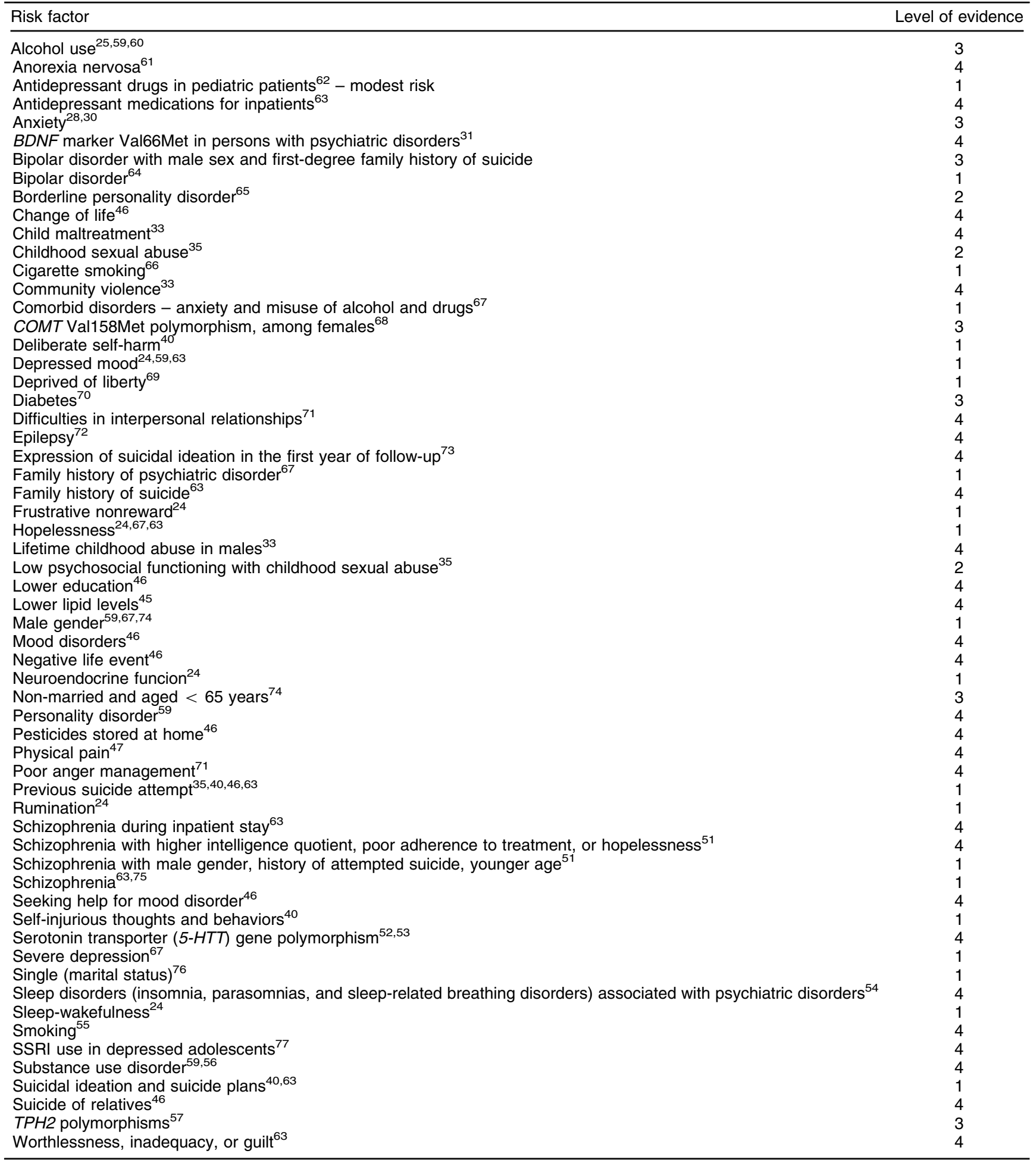

BDNF = brain derived neurotrophic factor; COMT = catechol-O-methyltransferase; SSRI = selective serotonin reuptake inhibitor.

factors for attempts and death, as these are the main outcomes to be prevented.

Except for the presence of a previous history, there are still no data in the literature that differentiate the risk factors for attempts or suicide throughout life from the risk factors for immediate events. Therefore, common clinical sense should always prevail in the assessment. 


\section{Genetic}

Suicidal behavior is high in family members of individuals who attempt or complete suicide. ${ }^{78}$ Evidence from a multitude of research designs (adoption, family, genome scan, geographical, immigrant, molecular genetics, surname, and twin studies of suicide) suggests genetic contributions to suicide risk. ${ }^{78,79}$ Heritability estimates of suicidal behavior from twin studies range from 30 to $55 \%$, and twin and family studies suggest that the genetic etiology of suicide attempt is partially distinct from that of psychiatric disorders themselves. ${ }^{48,78,79}$

The large number of published meta-analyses on the associations between single-nucleotide polymorphisms (SNPs) and suicidal behavior mirrors the enormous research interest in this topic. Although a previous meta-analysis observed similarities in some studies, the effect sizes were small and rarely statistically significant, and there was substantial heterogeneity. ${ }^{80}$ For this reason, and as it is a very well-studied area the results for which are constantly changing, we will limit ourselves to presenting only the most relevant positive results.

An association between serotonin transporter (5-HTT) gene polymorphisms and suicidal behavior (suicidal attempt and completed suicide) has been described. ${ }^{52,53}$ The brain-derived neurotrophic factor (BDNF) gene polymorphism Val66Met has also been reported in psychiatric disorders. ${ }^{31}$ In individuals who committed suicide, postmortem studies show changes in the methylation pattern or expression of some genes, in addition to a higher overall methylation rate. In patients with suicidal ideation, methylation in the promoter of the BDNF gene was found to inhibit its expression. ${ }^{81,82}$

In another study, a significant association was identified between the catechol-O-methyltransferase (COMT) gene polymorphism Val158Met and risk of suicide among women. ${ }^{68}$ There are also associations of tryptophan hydroxylase 2 (TPH2) polymorphisms with psychiatric disorders and suicidal behavior. ${ }^{57}$

In genome-wide association studies (GWAS) of attempted suicide, polygenic risk scores for major depression were significantly associated with suicide attempts in major depressive disorder $\left(R^{2}=0.25 \%\right)$, bipolar disorder $\left(R^{2}=0.24 \%\right)$, and schizophrenia $\left(R^{2}=0.40 \%\right){ }^{48}$

However, it is important to note that genetic changes in suicidal behavior are still controversial, and as one author concluded, at present, there is no identified gene directed linked to suicide. ${ }^{83}$

\section{Demographic data}

In absolute numbers, suicide mortality peaks in the 15-to29 age range. Among children aged 10 to 14, suicide is the third most common cause of death, and the second most common cause of death up to the age of 34 years. ${ }^{84}$ The ratio between men and women varies according to different studies and regions. ${ }^{59,67,84}$ Homosexual or bisexual orientation may also be a risk factor, ${ }^{42}$ as are being the only child in a family, ${ }^{46}$ having low educational attainment, ${ }^{46}$ being unmarried, ${ }^{76}$ and being in prison. ${ }^{69}$
Socioeconomic variables influence suicide rates only through their interaction with other risk factors and, mainly, with mental disorders. Several factors have been observed: age, sex, ethnicity, and related parameters; social status (low income, income inequality, unemployment, low education, and low social support); social change (urbanization and income change); neighborhood (inadequate housing, overcrowding, and violence); and environmental impacts (climate change, natural catastrophe, war, conflict, and migration). ${ }^{8,84}$

An important observation is that the definition of whether a variable is a risk or protective factor depends on the reference group. ${ }^{76}$ For example, according to the U.S. Centers for Disease Control and Prevention (CDC), people between the ages of 60 and 64 have a higher prevalence of deaths by suicide than children aged 5 to 9 years, but a lower prevalence rate of deaths by suicide than those aged 80 to 84 years. In this sense, being 60 to 64 years old is considered a risk factor for suicide only when compared to the pediatric age group. ${ }^{76,85}$ At the same time, being 60 to 64 years old can also be a protective factor when compared to the 80-to-84 age group. ${ }^{76}$ Age, sex, race and ethnicity, family types, education level, employment status, and socioeconomic status may be risk factors for suicidal attempt or suicidal death; whether these factors are particularly strong depends on the reference group. $^{76}$

\section{Psychological factors, stress, and external factors}

Some psychological stressors and other external factors associated with suicidal behavior include affiliation and attachment, ${ }^{24}$ arousal, ${ }^{24}$ bullying, ${ }^{33}$ change of life, ${ }^{46}$ child maltreatment, ${ }^{33}$ child sexual abuse, ${ }^{33-35}$ community violence, ${ }^{33}$ dating violence, ${ }^{33}$ difficulties in interpersonal relationships, ${ }^{71}$ exposure to self-injurious thoughts and behaviors of others (e.g., friends, family members, schoolmates, etc.), ${ }^{40}$ family history of self-injurious thoughts and behaviors, ${ }^{40}$ frustrative nonreward, ${ }^{24}$ hopelessness, ${ }^{24}$ impaired cognitive inhibition in affective disorders, ${ }^{43}$ impairment of cognitive systems (e.g., impulsiveness, attention problems), ${ }^{24}$ low psychosocial functioning with childhood sexual abuse, ${ }^{35}$ negative attributional style, ${ }^{24}$ negative life events, ${ }^{46}$ neuroticism, ${ }^{24}$ perception and understanding of self, ${ }^{24}$ poor anger management, ${ }^{71}$ poor relationship with families, ${ }^{46}$ rumination, ${ }^{24}$ and suicide of relatives. ${ }^{46}$

\section{Physical and health factors}

Few variables were significant for this category: neuroendocrine function, ${ }^{24}$ higher cortisol levels below age 40 years, ${ }^{41}$ and lower lipid levels ${ }^{45}$ are the main findings. Others include physical pain ${ }^{47}$ and sleep-wakefulness. ${ }^{24}$

\section{Suicidal behavior history}

Information on previous suicidal behavior is the most important and, together with treatment of mental illness, among those factors most amenable to intervention. Previous suicide attempts, ${ }^{35}$ self-injurious thoughts and 
behaviors, ${ }^{40}$ suicide ideation and suicide plans, ${ }^{40}$ suicide of relatives, ${ }^{46}$ deliberate self-harm ${ }^{40}$ (associated with other factors), expression of suicidal ideation in the first year of follow-up, ${ }^{73}$ and family history of suicide ${ }^{63}$ are the most relevant events.

Clinicians should be especially vigilant in cases of repetition of suicide attempts, maintenance of suicidal ideation despite all efforts at treatment, previous serious suicide attempts, and if suicidal behavior occurs in conjunction with active symptoms of mental illness.

\section{Nonsuicidal self-injury and suicidal behavior}

Not all cases of nonsuicidal self-injury and suicidal behavior are related to future attempts or suicide. Little information exists that can predict the groups at greatest risk. So far, the following factors have been identified as significant (level of evidence 4): non-suicidal self-injury (NSSI) frequency, number of NSSI methods, hopelessness, borderline personality disorder, impulsivity, posttraumatic stress disorder (PTSD), use of cutting as an NSSI method, and depression. ${ }^{44}$ Risk should also be considered when NSSI behavior is associated with other risk factors for suicidal behavior, especially previous suicide attempts, ${ }^{35}$ self-injurious thoughts and behaviors, ${ }^{40}$ suicide ideation and suicide plans, ${ }^{40}$ and suicide of relatives. ${ }^{46}$

\section{What mental illnesses are most related to suicidal behavior?}

Mood disorders ${ }^{46,59,71,86}$ are the main diagnosis associated with suicidal behavior. The second most frequent factor is substance use and abuse, including acute alcohol use, ${ }^{23}$ any alcohol use, ${ }^{46,59}$ substance use disorder, ${ }^{46,51,56,59}$ chronic cannabis use, ${ }^{36}$ and smoking. ${ }^{46,55}$ Other frequent diagnoses are personality disorder ${ }^{59}$ (especially borderline personality disorder), ${ }^{65}$ psychotic disorders such as schizophrenia, ${ }^{51}$ including schizophrenia with sleep disorder ${ }^{54}$ and schizophrenia with physical comorbidity or history of depression, family history of suicide or history of drug use or history of tobacco use or being white, and depressive symptoms, ${ }^{51}$ schizophrenia in males with history of attempted suicide and younger age, ${ }^{51}$ and schizophrenia with higher intelligence quotient or poor adherence to treatment or hopelessness. ${ }^{51}$ Anxiety disorders ${ }^{28}$ associated with suicide include panic disorder with sleep disorder ${ }^{54}$ and PTSD with sleep disorder. ${ }^{54}$ Other important diagnoses are anorexia nervosa, ${ }^{61}$ body dysmorphic disorder, ${ }^{87}$ and sleep disorders (insomnia, parasomnias, and sleep-related breathing disorders) in the presence of psychiatric disorders. ${ }^{54}$

Regardless of the diagnosis, it is important to remember that suicidal behavior is a complication of mental illness, and its presence means that improvement has not yet been achieved. Therefore, the presence of suicidal ideation and attempts must be regarded and addressed as the presence of an episode or crisis. Table 3 lists the main mental disorders related to suicidal behavior.
Table 3 Mental disorders related to suicidal behavior

\begin{tabular}{lc}
\hline Factor & Level of evidence \\
\hline Acute alcohol use $^{23}$ & 4 \\
Alcohol use $^{24,46,59}$ & 3 \\
Anorexia nervosa $^{61}$ & 4 \\
Anxiety disorders $^{28}$ & 4 \\
Bipolar disorder $^{32,59,64,88,89}$ & 1 \\
Body dysmorphic disorder $^{87}$ & 4 \\
Borderline personality disorder $^{65}$ & 2 \\
Depression with sleep disorder $^{54}$ & 4 \\
Depression $^{51,59,71,77}$ & 4 \\
Mood disorders $^{46,59,86}$ & 4 \\
Panic disorder with sleep disorder & 4 \\
Personality disorder $^{59}$ & 4 \\
Psychosis with depressive symptoms $^{38}$ & 1 \\
PTSD with sleep disorder $^{50,54}$ & 3 \\
Schizophrenia with sleep disorder $^{54}$ & 4 \\
Schizophrenia $^{63}$ & 4 \\
Schizophrenia $^{51,75}$ & 1 \\
Smoking $^{46,55}$ & 4 \\
Substance use disorder $^{46,51,56,59}$ & 4
\end{tabular}

PTSD = posttraumatic stress disorder.

\section{Does the use of antidepressants increase the risk of suicide?}

In the opinion of several experts, the use of antidepressants may increase the risk of suicide at the beginning of treatment. This information needs to be analyzed carefully. For the pediatric population, there is a modest increase in suicide. ${ }^{62}$ Antidepressant drugs may improve suicide attempts in the short term compared to a placebo, ${ }^{27}$ while selective serotonin reuptake inhibitor (SSRI) use may be related to completed suicide in depressed adolescents. $^{77}$

For youths, no significant effects of treatment on suicidal thoughts and behavior was found, although depression responded to treatment. No evidence of increased suicide risk was observed in youths receiving active medication. $^{90}$ In contrast, exposure to SSRIs almost doubled (odds ratio $[O R]=1.92$ ) the risk of suicide and suicide attempts among adolescents in these observational studies. It is possible that only the most severely ill adolescents would have been prescribed antidepressants, so this observational sample may well have had a particularly high risk for suicide actions. Nevertheless, caution and close monitoring are recommended when antidepressants are prescribed in this age group. ${ }^{91}$

Attention should be paid to the fact that bipolar disorder usually starts in childhood and can lead to a first depressive episode, which could result in the prescription of antidepressants, assuming a unipolar depressive episode. In these cases, there is still a risk of worsening symptoms of psychomotor agitation and impulsivity, which should already be a concern when prescribing antidepressants to the pediatric population.

On the other hand, in a meta-analysis, the prescription of fluoxetine and venlafaxine decreased suicidal thoughts and behaviors over time in adult and geriatric patients compared to a placebo by reducing depressive symptoms. For young people, no significant effects of treatment on suicidal thoughts and behavior were 
found, although depression responded to treatment. There was no evidence of an increased risk of suicide in young people taking medication. ${ }^{90}$ Another study concluded that the evidence supporting a causal link between antidepressant use and suicide in children is weak. ${ }^{92}$

What we propose, then, is that treatment is a way to reduce the risk of attempted and completed suicide; however, in the case of antidepressants, closer vigilance is needed in the first 30 days, especially in youths.

\section{Does assessing suicidality increase the risk of suicide?}

A meta-analysis concluded that assessing suicidality with regard to negative outcomes did not demonstrate significant iatrogenic effects or support the appropriateness of universal screening for suicidality, which should allay fears that assessing suicidality is harmful. ${ }^{93}$ Despite the apparently strong association between high-risk categorization and subsequent suicide, the low rate of inpatient suicide means that the predictive value of a high-risk categorization is below $2 \%$. It is recommended that hospitals develop safer environments by improving systems of care to reduce the suicide of psychiatric inpatients rather than conduct risk assessments. ${ }^{63}$ Therefore, such an approach to suicidal behavior cannot be a risk factor, but a protective factor.

\section{Conclusion for risk factors}

There are many risk factors for attempted and complete suicide, and there is no single factor capable of predicting short- or long-term events. Therefore, assessment must be complete, individualized, and consider the combination of multiple factors, with particular emphasis on personal and family history of suicidal behavior, presence of acute mental illness, and stressors that individuals have difficulty handling.

Table 4 Protective factors for suicide attempt and completed suicide

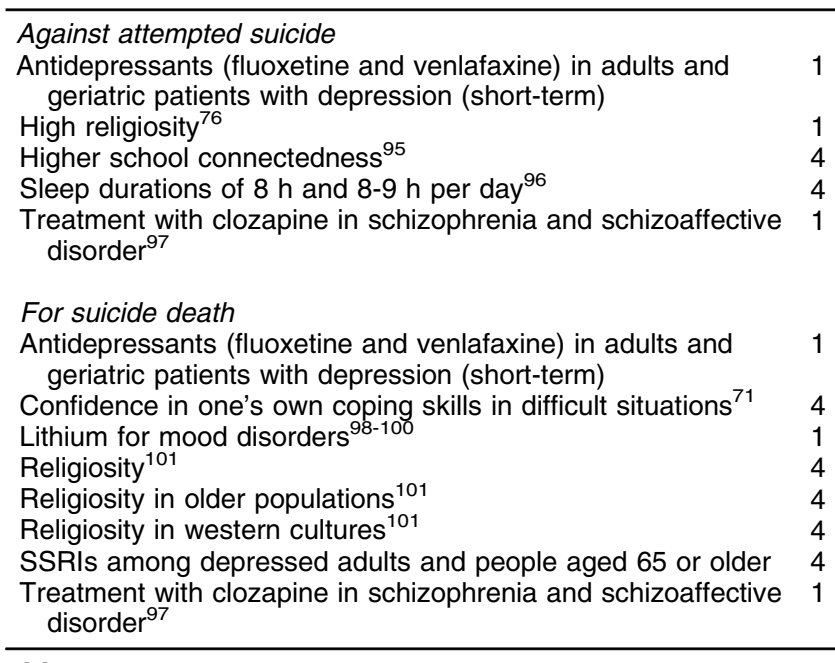

SSRI = selective serotonin reuptake inhibitor.

\section{Protective factors}

There are far fewer data on protective factors than on risk factors. Known protective factors are shown in Table 4. Such factors can reduce the chance of a new attempt or death. However, protective factors do not replace the presence of several risk factors, and the best measures to be offered to the patient are surveillance and treatment. It is noted that in some situations, psychopharmacological treatment is protective, again reinforcing the importance of treatment in preventing suicide. For medications, we present only the best available evidence in this table. Other options will be presented in the "Intervention" item in the next article in this guideline. ${ }^{94}$

\section{Conclusion for protective factors}

There are fewer protective factors identified in the literature, and the same rules that apply to risk factors apply to them. No single protective factor can be considered as a guarantee that a fatal event will not occur. The presence of protective factors helps, but does not replace treatment and monitoring. Patients with protective factors but with multiple risk factors should be handled with caution.

\section{Assessment}

There is no effective model capable of predicting suicidal behavior, and its cause is multifactorial. The evaluation needs to be as broad as possible. On the other hand, suicidal behavior is a common health situation, which can overburden the system if long-term models are chosen. In addition, suicide is a medical emergency, and it requires rapid and effective evaluation. For this reason, a structured assessment focused on essential information is recommended.

An important finding suggests that 11 and $50 \%$ of individuals with suicidal behavior who were treated in an emergency service either declined or abandoned outpatient treatment, respectively. ${ }^{102}$ Therefore, careful evaluation focusing on the development of a therapeutic alliance from the very first contact is essential.

The first step recommended by this guideline, which is ignored in several documents, is to rule out other medical emergencies that require immediate care, such as trauma and poisoning. Health professionals can often neglect such situations in favor of overvaluing psychic symptoms and suicidal behavior. Instead, care of the suicidal patient should begin as in any other medical emergency.

During the assessment, the psychiatrist obtains information about the patient's psychiatric and other medical history and current mental status. This information allows the psychiatrist to identify risk and protective factors for suicide, which may require acute interventions. ${ }^{19,103,104}$ It also allows immediate patient safety concerns to be addressed and helps determine the most appropriate scenario for treatment, as well as develop a differential diagnosis to guide treatment planning. ${ }^{19,103}$ The breadth and depth of psychiatric assessment aimed specifically at assessing the risk of suicide varies according to the environment, the patient's ability to provide information, and availability of information from other sources. ${ }^{103}$ 
Although assessment scales for suicidal behavior are available, they do not have the necessary predictive validity for use in routine clinical practice, and should be considered only complementary. ${ }^{103}$

We recommend that the priority assessment be based on the Practice Guideline for the Assessment and Treatment of Patients with Suicidal Behaviors. ${ }^{103}$

\section{Current and past presentation of suicidal behavior}

Specifically, healthcare professionals should inquire about suicidal thoughts, plans, and behavior, specific methods considered for suicide (including their lethality and the patient's expectation about lethality, as well as whether firearms are accessible), evidence of hopelessness, impulsiveness, anhedonia, panic attacks, or anxiety, reasons for living and plans for the future, alcohol or other substance use associated with the current presentation, and thoughts, plans, or intentions of violence toward others. ${ }^{103}$ This detailed information must be obtained at each attempt. ${ }^{103}$

\section{Psychiatric illness}

Healthcare professionals should determine the presence or absence of signs and symptoms associated with specific psychiatric diagnoses and identify specific psychiatric symptoms that may influence suicide risk. ${ }^{103}$

\section{Past history}

Healthcare professionals should review the psychiatric history (e.g., previous and comorbid diagnoses, prior hospitalizations, and other treatment, past suicidal ideation), history of medical treatment (e.g., identify medically serious suicide attempts and past or current medical diagnoses), as well as gauge the strength and stability of current and past therapeutic relationships. ${ }^{103}$

\section{Family history}

Healthcare professionals should inquire about family history of suicide and suicide attempts and psychiatric hospitalizations or mental illness, including substance use disorders; determine the circumstances of suicides in first-degree relatives, including the patient's involvement and the patient's and relative's ages at the time; and determine the childhood and current family milieu, including history of family conflict or separation, parental legal trouble, family substance use, domestic violence, and physical and/or sexual abuse. ${ }^{103}$

\section{Psychosocial situation}

Healthcare professionals should consider acute psychosocial crises or chronic psychosocial stressors that may augment suicide risk (e.g., financial or legal difficulties, interpersonal conflicts or losses, stressors in gay, lesbian, or bisexual youths, housing problems, job loss, and educational failure). ${ }^{71,103}$

\section{Individual strengths and vulnerabilities}

Healthcare professionals should consider how coping skills, personality traits, thinking style, and developmental and psychological needs may affect the patient's suicide risk and the formulation of the treatment plan. ${ }^{103}$

Some structured and simplified interviews can assist in the assessment of risk and protection factors, which in turn can assist in planning interventions. For example, D'Onofrio et al. ${ }^{105}$ has developed a 10- to 15-minute approach that includes screening, brief intervention, and referral to treatment. ${ }^{102}$ Another similar model is the socalled security planning intervention (SPI). It is indicated for patients in emergency departments, trauma centers, telephone helplines, psychiatric inpatient units, and other acute care settings. The SPI consists of a list of coping strategies and sources of support that patients can use to alleviate a suicide crisis. ${ }^{102}$

The Emergency Department Safety Assessment and Follow-Up Evaluation (ED-SAFE) assessed screening and intervention in a single study. The authors concluded that universal screening plus intervention was more effective in preventing suicides compared with universal screening added to treatment as usual and treatment as usual alone. ${ }^{106,107}$ In response, we propose, under the name of "Safety Plan," an approach in which assessment (including of risk and protection factors) is conducted in sequence with therapeutic measures. Such focused

Table 5 Scales for suicidal behavior assessment

\begin{tabular}{|c|c|c|}
\hline Scale & Indication & Level of evidence \\
\hline \multicolumn{3}{|l|}{ Suicide attempt } \\
\hline Patient Health Questionnaire-9 (PHQ-9) ${ }^{108}$ & Patients with depression/anxiety disorder & 3 \\
\hline SAD PERSONS Scale (SPS) ${ }^{108}$ & Patients in psychiatric emergency care & 2 \\
\hline Manchester Self-Harm Rule (MSHR) ${ }^{108}$ & Patients presenting after self-harm/suicide attempt & 2 \\
\hline Early Recollections Rating Scale (ERRS) ${ }^{108}$ & Presenting after self-harm/suicide attempt & 3 \\
\hline $\begin{array}{l}\text { Recent self-harm in the past year - Alone or homeless, } \\
\text { Cutting used as a method of harm, Treatment for a psychiatric } \\
\text { disorder (ReACT) })^{108}\end{array}$ & Presenting after self-harm/suicide attempt & 3 \\
\hline Södersjukhuset self-harm rule (SOS-4) ${ }^{108}$ & Presenting after self-harm/suicide attempt & 2 \\
\hline \multicolumn{3}{|l|}{ Complete suicide } \\
\hline Beck Hopelessness Scale (BHS) ${ }^{108}$ & Depression/anxiety disorder & 3 \\
\hline Scale for Suicide Ideation-Worst (SSI-W) ${ }^{108}$ & Depression/anxiety disorder & 3 \\
\hline $\operatorname{ReACT}$ & Presenting after self-harm/suicide attempt & 3 \\
\hline
\end{tabular}



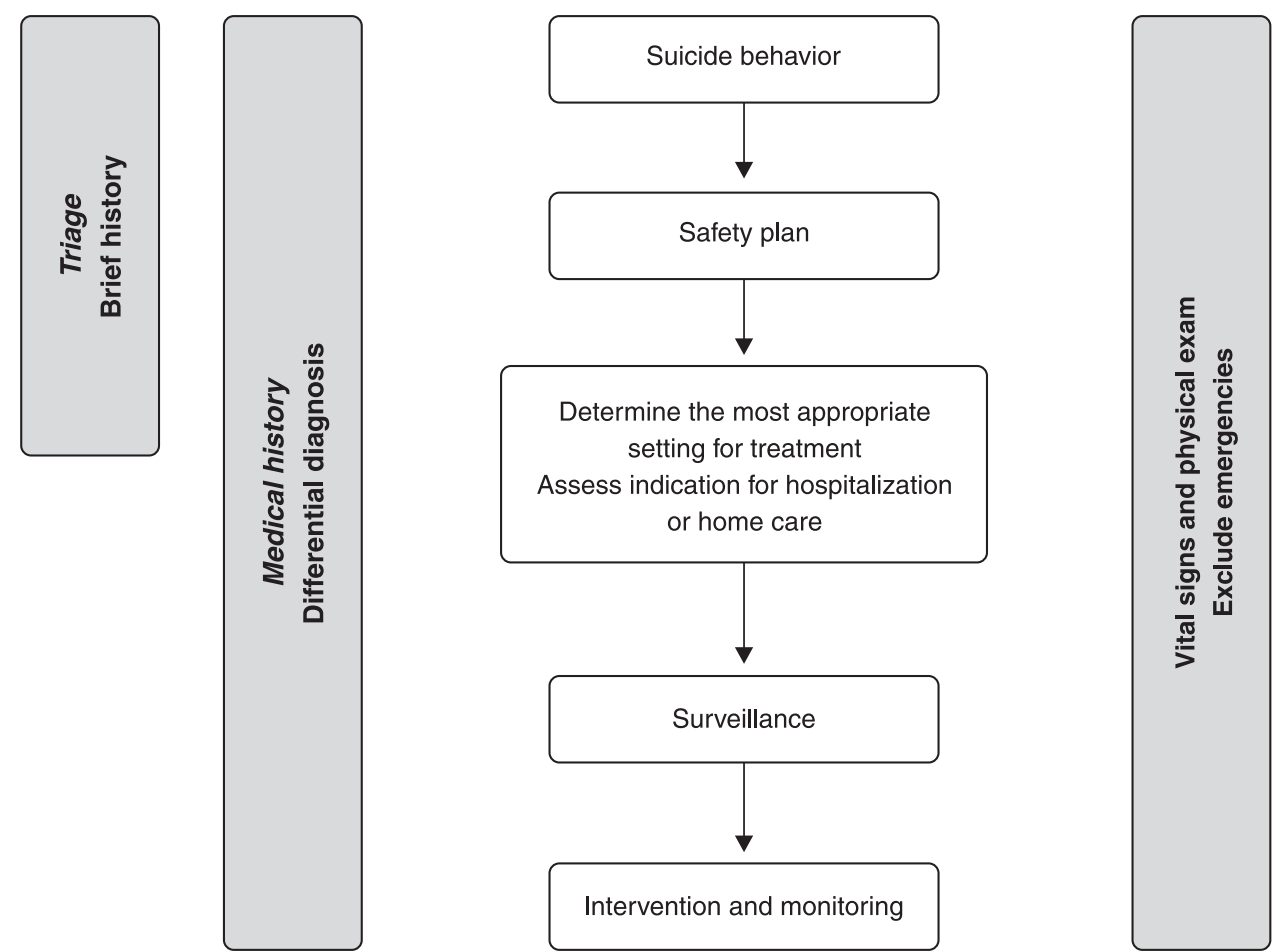

Figure 2 Flow diagram for management of suicidal behavior, with a focus on emergency settings.

assessment can be more effective and save time and costs. ${ }^{102,106,107}$

\section{Scales}

None of the available instruments for assessment of suicidality reached the predetermined benchmarks $(80 \%$ sensitivity and $50 \%$ specificity) for the suicide outcome. ${ }^{108}$ Since most scales are unable to evaluate and predict a future attempted or complete suicide with good precision, no single scale or measure can be recommended to replace a comprehensive evaluation performed by a psychiatrist. Such instruments have only complementary value and must be preceded by a thorough history, physical and psychological examination, and assessment of risk and protection factors. Suggested scales for complementary use are listed in Table 5.

\section{Conclusion for assessment}

Considering the complexity of the assessment of risk and protection factors and uniting the need for a special assessment for patients with suicidal behavior, we suggest the use of the Safety Plan technique, which combines assessment with intervention. This technique will be discussed in the next article of this series. ${ }^{94}$

\section{Conclusion}

In conclusion, this first part of the guidelines discussed the importance of assessing suicidal behavior, especially in regard to risk and protective factors. Based on the discussion, we propose a flow diagram for suicidal behavior management (Figure 2). A focused assessment can be more effective and save time and costs, especially if combined with intervention measures. ${ }^{94}$

\section{Disclosure}

LB has served as a speaker for Libbs and a scientific consultant for Apsen. GAR has served as speaker for Pfizer, Lundbeck, Servier, Libbs, Takeda, FQM, and Genon, and received assistance for events from Torrent, Daichi Sankyo, Janssen, and Aché. AM has served as a consultant for Abbott, Jansen, Aché, Cristália, Libbs, Pfizer, Torrent, Eurofarma, Medley, Sanofi-Aventis, and Allergan; as a board advisor for Cristália, Jansen, and Libbs; as a speaker for Abbott, Aché, Cristália, Jansen, Libbs, Pfizer, and Eurofarma; receives copyrights from Guanabara Koogan; and received assistance for events from Eurofarma and Cristália. HC has served as a speaker for Janssen, Sanofi, Servier, and EMS; as a medical writer for EMS; and as a board advisor for Janssen. TCT has served on advisory boards for Janssen-Cilag, Lundbeck, Servier, Abbott, Medley, Takeda, SEM, and Torrent; and received grant or research support from Abbott, Libbs, Lundbeck, Medley, Aché, Torrent, Biolab Sanus, Pfizer, Servier, Apsen, and EMS. JQ has received clinical research support from LivaNova; has speaker bureau membership with Myriad Neuroscience, Janssen Pharmaceuticals, and Abbvie; is a stockholder at Instituto de Neurociências Dr. Joao Quevedo; and receives copyrights from Artmed Editora, Artmed Panamericana, and Elsevier/Academic Press. The other authors report no conflicts of interest. 


\section{References}

1 Fleck MPA. Emergências psiquiátricas. In: Taborda J, Lima P. Rotinas em psiquiatria. Porto Alegre: Artmed;1996.

2 Baldaçara L, Ismael F, Leite V, Pereira LA, dos Santos RM, Gomes Júnior VP, et al. Brazilian guidelines for the management of psychomotor agitation. Part 1. Non-pharmacological approach. Braz J Psychiatry. 2019;41:153-67.

3 Menegon GL, Piccin J, Caldieraro MA, Fleck MPA. Avaliação do paciente na emergência. In: Quevedo J, Carvalho AF. Emergências psiquiátricas. Porto Alegre: Artmed;2014.

4 Barros RE, Marques JM, Carlotti IP, Zuardi AW, Del-Ben CM. Short admission in an emergency psychiatry unit can prevent prolonged lengths of stay in a psychiatric institution. Braz J Psychiatry. 2010; 32:145-51.

5 Cruz CM, Leiva JL, Borgoño RV, Larach TK, Errázuriz LB, Chianale IC, et al. Epidemiología de la urgencia psiquiátrica en el Instituto Psiquiátrico "Dr. José Horwitz": un nuevo estudio comparativo. Rev Chil Neuropsiquiatr. 2010;48:175-83.

6 Rodrigues CD, de Souza DS, Rodrigues HM, Konstantyner TC. Trends in suicide rates in Brazil from 1997 to 2015. Braz J Psychiatry. 2019;41:380-8.

7 Piccin J, Manfro PH, Caldieraro MA, Kieling C. The research output on child and adolescent suicide in Brazil: a systematic review of the literature. Braz J Psychiatry. 2020;42:209-13.

8 Alarcão AC, Dell' Agnolo CM, Vissoci JR, Carvalho EC, Staton CA, de Andrade L, et al. Suicide mortality among youth in southern Brazil: a spatiotemporal evaluation of socioeconomic vulnerability. Braz J Psychiatry. 2020;42:46-53.

9 Naghavi M; Global Burden of Disease Self-Harm Collaborators. Global, regional, and national burden of suicide mortality 1990 to 2016: systematic analysis for the global burden of disease study 2016. BMJ. 2019;364:I94.

10 Fazel S, Runeson B. Suicide. N Engl J Med. 2020;382:266-74.

11 World Health Organization (WHO). Global Health Observatory (GHO) data [Internet]. [cited 2020 Jul 7]. www.who.int/gho/mental_ health/suicide_rates/en/.

12 Korczak DJ, Finkelstein Y, Barwick M, Chaim G, Cleverley K, Henderson $\mathrm{J}$, et al. A suicide prevention strategy for youth presenting to the emergency department with suicide related behaviour: protocol for a randomized controlled trial. BMC Psychiatry. 2020;20:20.

13 Dantas AP, de Azevedo UN, Nunes AD, Amador AE, Marques MV Barbosa IR. Analysis of suicide mortality in Brazil: spatial distribution and socioeconomic context. Braz J Psychiatry. 2018;40:12-8.

14 Meyer RE, Salzman C, Youngstrom EA, Clayton PJ, Goodwin FK, Mann JJ, et al. Suicidality and risk of suicide--definition, drug safety concerns, and a necessary target for drug development: a consensus statement. J Clin Psychiatry. 2010;71:e1-21.

15 Posner K, Oquendo MA, Gould M, Stanley B, Davies M. Columbia Classification Algorithm of Suicide Assessment (C-CASA): classification of suicidal events in the FDA's pediatric suicidal risk analysis of antidepressants. Am J Psychiatry. 2007;164:1035-43.

16 Large M, Kaneson M, Myles N, Myles H, Gunaratne P, Ryan C. Meta-analysis of longitudinal cohort studies of suicide risk assessment among psychiatric patients: heterogeneity in results and lack of improvement over time. PLoS One. 2016;11:e0156322.

17 Large M, Myles N, Myles H, Corderoy A, Weiser M, Davidson M, et al. Suicide risk assessment among psychiatric inpatients: a systematic review and meta-analysis of high-risk categories. Psychol Med. 2018;48:1119-27.

18 Zalsman G, Hawton K, Wasserman D, van Heeringen K, Arensman $\mathrm{E}$, Sarchiapone $\mathrm{M}$, et al. Suicide prevention strategies revisited: 10-year systematic review. Lancet Psychiatry. 2016;3:646-59.

19 Baldaçara L, Cordeiro DC, Calfat ELB, Cordeiro DC, Chung TC. Emergências psiquiátricas. Rio de Janeiro: Elsevier; 2019.

20 Belsher BE, Smolenski DJ, Pruitt LD, Bush NE, Beech EH, Workman $\mathrm{DE}$, et al. Prediction models for suicide attempts and deaths: a systematic review and simulation. JAMA Psychiatry. 2019;76:642-51.

21 Posner K, Brown GK, Stanley B, Brent DA, Yershova KV, Oquendo MA, et al. The Columbia-suicide severity rating scale: initial validity and internal consistency findings from three multisite studies with adolescents and adults. Am J Psychiatry. 2011;168:1266-77.

22 Large M, Sharma S, Cannon E, Ryan C, Nielssen O. Risk factors for suicide within a year of discharge from psychiatric hospital: a systematic meta-analysis. Aust N Z J Psychiatry. 2011;45: 619-28.

23 Borges G, Bagge CL, Cherpitel CJ, Conner KR, Orozco R, Rossow I. A meta-analysis of acute use of alcohol and the risk of suicide attempt. Psychol Med. 2017;47:949-57.

24 Glenn CR, Kleiman EM, Cha CB, Deming CA, Franklin JC, Nock MK. Understanding suicide risk within the research domain criteria (RDoC) framework: a meta-analytic review. Depress Anxiety. 2018; 35:65-88.

25 Darvishi N, Farhadi M, Haghtalab T, Poorolajal J. Alcohol-related risk of suicidal ideation, suicide attempt, and completed suicide: a meta-analysis. PLoS One. 2015;10:e0126870.

26 Bridge JA, lyengar S, Salary CB, Barbe RP, Birmaher B, Pincus HA, et al. Clinical response and risk for reported suicidal ideation and suicide attempts in pediatric antidepressant treatment: a meta-analysis of randomized controlled trials. JAMA. 2007;297: 1683-96.

27 Mosholder AD, Willy M. Suicidal adverse events in pediatric randomized, controlled clinical trials of antidepressant drugs are associated with active drug treatment: a meta-analysis. J Child Adolesc Psychopharmacol. 2006;16:25-32.

28 Kanwar A, Malik S, Prokop LJ, Sim LA, Feldstein D, Wang Z, et al. The association between anxiety disorders and suicidal behaviors: a systematic review and meta-analysis. Depress Anxiety. 2013;30: 917-29.

29 Bentley KH, Franklin JC, Ribeiro JD, Kleiman EM, Fox KR, Nock MK. Anxiety and its disorders as risk factors for suicidal thoughts and behaviors: a meta-analytic review. Clin Psychol Rev. 2016; 43:30-46.

30 Liu J, Fang Y, Gong J, Cui X, Meng T, Xiao B, et al. Associations between suicidal behavior and childhood abuse and neglect: a meta-analysis. J Affect Disord. 2017;220:147-55.

31 Zai CC, Manchia M, De Luca V, Tiwari AK, Chowdhury NI, Zai GC, et al. The brain-derived neurotrophic factor gene in suicidal behaviour: a meta-analysis. Int J Neuropsychopharmacol. 2012;15:1037-42.

32 Novick DM, Swartz HA, Frank E. Suicide attempts in bipolar I and bipolar II disorder: a review and meta-analysis of the evidence. Bipolar Disord. 2010;12:1-9.

33 Castellvi P, Miranda-Mendizabal A, Pares-Badell O, Almenara J, Alonso I, Blasco MJ, et al. Exposure to violence, a risk for suicide in youths and young adults. A meta-analysis of longitudinal studies. Acta Psychiatr Scand. 2017;135:195-211.

34 Brewer-Smyth K. Obesity, traumatic brain injury, childhood abuse, and suicide attempts in females at risk. Rehabil Nurs. 2014;39: 183-91.

35 Grendas LN, Rojas SM, Puppo S, Vidjen P, Portela A, Chiapella L, et al. Interaction between prospective risk factors in the prediction of suicide risk. J Affect Disord. 2019;258:144-50.

36 Borges G, Bagge CL, Orozco R. A literature review and meta-analyses of cannabis use and suicidality. J Affect Disord. 2016;195: 63-74.

37 Wang YH, Shi ZT, Luo QY. Association of depressive symptoms and suicidal ideation among university students in China: a systematic review and meta-analysis. Medicine (Baltimore). 2017;96: e6476.

38 McGinty J, Haque MS, Upthegrove R. Depression during first episode psychosis and subsequent suicide risk: a systematic review and meta-analysis of longitudinal studies. Schizophr Res. 2018; 195:58-66.

39 Zatti C, Rosa V, Barros A, Valdivia L, Calegaro VC, Freitas LH, et al. Childhood trauma and suicide attempt: a meta-analysis of longitudinal studies from the last decade. Psychiatry Res. 2017;256: 353-8.

40 Ribeiro JD, Franklin JC, Fox KR, Bentley KH, Kleiman EM, Chang $\mathrm{BP}$, et al. Self-injurious thoughts and behaviors as risk factors for future suicide ideation, attempts, and death: a meta-analysis of longitudinal studies. Psychol Med. 2016;46:225-36.

41 O'Connor DB, Ferguson E, Green JA, O'Carroll RE, O'Connor RC. Cortisol levels and suicidal behavior: a meta-analysis. Psychoneuroendocrinology. 2016;63:370-9.

42 Miranda-Mendizabal A, Castellvi P, Pares-Badell O, Almenara J, Alonso I, Blasco MJ, et al. Sexual orientation and suicidal behaviour in adolescents and young adults: systematic review and metaanalysis. Br J Psychiatry. 2017;211:77-87. 
43 Richard-Devantoy S, Gorwood P, Annweiler C, Olie JP, Le Gall D, Beauchet $O$. Suicidal behaviours in affective disorders: a deficit of cognitive inhibition? Can J Psychiatry. 2012;57:254-62.

44 Victor SE, Klonsky ED. Correlates of suicide attempts among self-injurers: a meta-analysis. Clin Psychol Rev. 2014;34:282-97.

45 Wu S, Ding Y, Wu F, Xie G, Hou J, Mao P. Serum lipid levels and suicidality: a meta-analysis of 65 epidemiological studies. J Psychiatry Neurosci. 2016;41:56-69.

$46 \mathrm{Li} \mathrm{Y,} \mathrm{Li} \mathrm{Y,} \mathrm{Cao} \mathrm{J.} \mathrm{Factors} \mathrm{associated} \mathrm{with} \mathrm{suicidal} \mathrm{behaviors} \mathrm{in}$ mainland China: a meta-analysis. BMC Public Health. 2012;12:524.

47 Calati R, Bakhiyi CL, Artero S, Ilgen M, Courtet P. The impact of physical pain on suicidal thoughts and behaviors: meta-analyses. J Psychiatr Res. 2015;71:16-32.

48 Mullins N, Bigdeli TB, Borglum AD, Coleman JR, Demontis D, Mehta $D$, et al. GWAS of suicide attempt in psychiatric disorders and association with major depression polygenic risk scores. Am J Psychiatry. 2019;176:651-60.

49 Gournellis R, Tournikioti K, Touloumi G, Thomadakis C, Michalopoulou PG, Christodoulou C, et al. Psychotic (delusional) depression and suicidal attempts: a systematic review and meta-analysis. Acta Psychiatr Scand. 2018;137:18-29.

50 Panagioti M, Gooding PA, Triantafyllou K, Tarrier N. Suicidality and posttraumatic stress disorder (PTSD) in adolescents: a systematic review and meta-analysis. Soc Psychiatry Psychiatr Epidemiol. 2015;50:525-37.

51 Cassidy RM, Yang F, Kapczinski F, Passos IC. Risk factors for suicidality in patients with schizophrenia: a systematic review, metaanalysis, and meta-regression of 96 studies. Schizophr Bull. 2018; 44:787-97.

$52 \mathrm{Li} \mathrm{D,} \mathrm{He} \mathrm{L.} \mathrm{Meta-analysis} \mathrm{supports} \mathrm{association} \mathrm{between} \mathrm{serotonin}$ transporter (5-HTT) and suicidal behavior. Mol Psychiatry. 2007; 12:47-54.

53 Anguelova M, Benkelfat C, Turecki G. A systematic review of association studies investigating genes coding for serotonin receptors and the serotonin transporter: II. Suicidal behavior. Mol Psychiatry. 2003;8:646-53.

54 Malik S, Kanwar A, Sim LA, Prokop LJ, Wang Z, Benkhadra K, et al. The association between sleep disturbances and suicidal behaviors in patients with psychiatric diagnoses: a systematic review and meta-analysis. Syst Rev. 2014;3:18.

55 Poorolajal J, Darvishi N. Smoking and suicide: a meta-analysis. PLoS One. 2016;11:e0156348.

56 Poorolajal J, Haghtalab T, Farhadi M, Darvishi N. Substance use disorder and risk of suicidal ideation, suicide attempt and suicide death: a meta-analysis. J Public Health (Oxf). 2016;38:e282-91.

57 Ottenhof KW, Sild M, Levesque ML, Ruhe HG, Booij L. TPH2 polymorphisms across the spectrum of psychiatric morbidity: a systematic review and meta-analysis. Neurosci Biobehav Rev. 2018;92:29-42.

58 Milner A, Page A, LaMontagne AD. Long-term unemployment and suicide: a systematic review and meta-analysis. PLoS One. 2013;8: e51333.

59 Arsenault-Lapierre G, Kim C, Turecki G. Psychiatric diagnoses in 3275 suicides: a meta-analysis. BMC Psychiatry. 2004;4:37.

60 Birckmayer J, Hemenway D. Minimum-age drinking laws and youth suicide, 1970-1990. Am J Public Health. 1999;89:1365-8.

61 Pompili M, Mancinelli I, Girardi P, Ruberto A, Tatarelli R. Suicide in anorexia nervosa: a meta-analysis. Int J Eat Disord. 2004;36:99-103.

62 Hammad TA, Laughren T, Racoosin J. Suicidality in pediatric patients treated with antidepressant drugs. Arch Gen Psychiatry. 2006;63:332-9.

63 Large M, Smith G, Sharma S, Nielssen O, Singh SP. Systematic review and meta-analysis of the clinical factors associated with the suicide of psychiatric in-patients. Acta Psychiatr Scand. 2011;124: 18-29.

64 Hayes JF, Miles J, Walters K, King M, Osborn DP. A systematic review and meta-analysis of premature mortality in bipolar affective disorder. Acta Psychiatr Scand. 2015;131:417-25.

65 Pompili M, Girardi P, Ruberto A, Tatarelli R. Suicide in borderline personality disorder: a meta-analysis. Nord J Psychiatry. 2005;59: 319-24.

66 Li D, Yang X, Ge Z, Hao Y, Wang Q, Liu F, et al. Cigarette smoking and risk of completed suicide: a meta-analysis of prospective cohort studies. J Psychiatr Res. 2012;46:1257-66.
67 Hawton K, Casanas CC, Haw C, Saunders K. Risk factors for suicide in individuals with depression: a systematic review. J Affect Disord. 2013;147:17-28.

68 Sadeghiyeh T, Biouki FH, Mazaheri M, Zare-Shehneh M, Neamatzadeh H, Poursharif Z. Association between Catechol-OMethyltransferase Val158Met (158G/A) polymorphism and suicide susceptibility: a meta-analysis. J Res Health Sci. 2017;17:e00383.

69 Zlodre J, Fazel S. All-cause and external mortality in released prisoners: systematic review and meta-analysis. Am J Public Health. 2012;102:e67-75.

70 Wang B, An X, Shi X, Zhang JA. Management of endocrine disease: suicide risk in patients with diabetes: a systematic review and metaanalysis. Eur J Endocrinol. 2017;177:R169-81.

71 de la Paz Maino M, Morales S, Echavarri O, Barros J, García A, Moya C, et al. Suicide risk configuration system in a clustered clinical sample: a generalized linear model obtained through the LASSO technique. Braz J Psychiatry. 2019;41:112-21.

72 Pompili M, Girardi P, Ruberto A, Tatarelli R. Suicide in the epilepsies: a meta-analytic investigation of 29 cohorts. Epilepsy Behav. 2005; 7:305-10.

73 Hubers AA, Moaddine S, Peersmann SH, Stijnen T, van Duijn E, van der Mast RC, et al. Suicidal ideation and subsequent completed suicide in both psychiatric and non-psychiatric populations: a metaanalysis. Epidemiol Psychiatr Sci. 2018;27:186-98.

74 Kyung-Sook W, SangSoo S, Sangjin S, Young-Jeon S. Marital status integration and suicide: a meta-analysis and meta-regression. Soc Sci Med. 2018;197:116-26.

75 Palmer BA, Pankratz VS, Bostwick JM. The lifetime risk of suicide in schizophrenia: a reexamination. Arch Gen Psychiatry. 2005;62: 247-53.

76 Huang X, Ribeiro JD, Musacchio KM, Franklin JC. Demographics as predictors of suicidal thoughts and behaviors: a meta-analysis. PLoS One. 2017;12:e0180793.

77 Barbui C, Esposito E, Cipriani A. Selective serotonin reuptake inhibitors and risk of suicide: a systematic review of observational studies. CMAJ. 2009;180:291-7.

78 Brent DA, Mann JJ. Family genetic studies, suicide, and suicidal behavior. Am J Med Genet C Semin Med Genet. 2005;133C:13-24.

79 Voracek M, Loibl LM. Genetics of suicide: a systematic review of twin studies. Wien Klin Wochenschr. 2007;119:463-75.

80 Schild AH, Pietschnig J, Tran US, Voracek M. Genetic association studies between SNPs and suicidal behavior: a meta-analytical field synopsis. Prog Neuropsychopharmacol Biol Psychiatry. 2013; 46:36-42.

81 Pawlak J, Dmitrzak-Weglarz M, Wilkosc M, Szczepankiewicz A, Leszczynska-Rodziewicz A, Zaremba D, et al. Suicide behavior as a quantitative trait and its genetic background. J Affect Disord. 2016;206:241-50.

82 Tombacz D, Maroti Z, Kalmar T, Csabai Z, Balázs Z, Takahashi S, et al. High-coverage whole-exome sequencing identifies candidate genes for suicide in victims with major depressive disorder. Sci Rep. 2017;7:7106.

$83 \mathrm{Li} \mathrm{D}, \mathrm{He} \mathrm{L}$. Further clarification of the contribution of the tryptophan hydroxylase (TPH) gene to suicidal behavior using systematic allelic and genotypic meta-analyses. Hum Genet. 2006;119:233-40.

84 Bachmann S. Epidemiology of suicide and the psychiatric perspective. Int J Environ Res Public Health. 2018;15:1425.

85 Centers for Disease Control and Prevention (CDC). Web-based injury statistics query and reporting system (WISQARS) [Internet]. 2017 [cited 2020 Jul 7]. https://healthdata.gov/dataset/web-basedinjury-statistics-query-and-reporting-system-wisqars.

86 Bowers L, Banda T, Nijman H. Suicide inside: a systematic review of inpatient suicides. J Nerv Ment Dis. 2010;198:315-28.

87 Angelakis I, Gooding PA, Panagioti M. Suicidality in body dysmorphic disorder (BDD): a systematic review with meta-analysis. Clin Psychol Rev. 2016;49:55-66.

88 Schaffer A, Isometsa ET, Tondo L, Moreno DH, Turecki G, Reis C, et al. International society for bipolar disorders task force on suicide: meta-analyses and meta-regression of correlates of suicide attempts and suicide deaths in bipolar disorder. Bipolar Disord. 2015;17:1-16.

89 Tondo L, Pompili M, Forte A, Baldessarini RJ. Suicide attempts in bipolar disorders: comprehensive review of 101 reports. Acta Psychiatr Scand. 2016;133:174-86. 
90 Gibbons RD, Brown CH, Hur K, Davis J, Mann JJ. Suicidal thoughts and behavior with antidepressant treatment: reanalysis of the randomized placebo-controlled studies of fluoxetine and venlafaxine. Arch Gen Psychiatry. 2012;69:580-7.

91 Kennedy SH, Lam RW, McIntyre RS, Tourjman SV, Bhat V, Blier P, et al. Canadian network for mood and anxiety treatments (CANMAT) 2016 clinical guidelines for the management of adults with major depressive disorder: section 3. Pharmacological treatments. Can J Psychiatry. 2016;61:540-60.

92 Kaizar EE, Greenhouse JB, Seltman H, Kelleher K. Do antidepressants cause suicidality in children? A Bayesian meta-analysis. Clin Trials. 2006;3:73-90; discussion 91-8.

93 DeCou CR, Schumann ME. On the iatrogenic risk of assessing suicidality: a meta-analysis. Suicide Life Threat Behav. 2018;48: 531-43.

94 Baldaçara L. Brazilian Psychiatric Association guidelines for the management of suicide behavior. Part 2. Screening, intervention, and prevention. Braz J Psychiatry. Forthcoming 2020.

95 Marraccini ME, Brier ZM. School connectedness and suicidal thoughts and behaviors: a systematic meta-analysis. Sch Psychol Q. 2017;32:5-21.

96 Chiu HY, Lee HC, Chen PY, Lai YF, Tu YK. Associations between sleep duration and suicidality in adolescents: a systematic review and dose-response meta-analysis. Sleep Med Rev. 2018;42:119-26.

97 Hennen J, Baldessarini RJ. Suicidal risk during treatment with clozapine: a meta-analysis. Schizophr Res. 2005;73:139-45

98 Baldessarini RJ, Tondo L, Davis P, Pompili M, Goodwin FK, Hennen J. Decreased risk of suicides and attempts during long-term lithium treatment: a meta-analytic review. Bipolar Disord. 2006;8:625-39.

99 Cipriani A, Pretty H, Hawton K, Geddes JR. Lithium in the prevention of suicidal behavior and all-cause mortality in patients with mood disorders: a systematic review of randomized trials. Am J Psychiatry. 2005;162:1805-19.

100 Plans L, Barrot C, Nieto E, Rios J, Schulze TG, Papiol S, et al. Association between completed suicide and bipolar disorder: a systematic review of the literature. J Affect Disord. 2019;242:111-22.

101 Wu A, Wang JY, Jia CX. Religion and completed suicide: a metaanalysis. PLoS One. 2015;10:e0131715.

102 Stanley B, Brown GK, Currier GW, Lyons C, Chesin M, Knox KL. Brief intervention and follow-up for suicidal patients with repeat emergency department visits enhances treatment engagement. Am J Public Health. 2015;105:1570-2.

103 Practice guideline for the assessment and treatment of patients with suicidal behaviors. Am J Psychiatry. 2003;160(11 Suppl):1-60.

104 Meleiro A. Psiquiatria: estudos fundamentais. Rio de Janeiro: Guanabara Koogan; 2018.

105 D'Onofrio G, Pantalon MV, Degutis LC, Fiellin DA, O'connor PG. Development and implementation of an emergency practitionerperformed brief intervention for hazardous and harmful drinkers in the emergency department. Acad Emerg Med. 2005;12:249-56.

106 Boudreaux ED, Miller I, Goldstein AB, Sullivan AF, Allen MH, Manton AP, et al. The emergency department safety assessment and follow-up evaluation (ED-SAFE): method and design considerations. Contemp Clin Trials. 2013;36:14-24.

107 Dunlap LJ, Orme S, Zarkin GA, Arias SA, Miller IW, Camargo CA Jr, et al. Screening and intervention for suicide prevention: a costeffectiveness analysis of the ED-SAFE interventions. Psychiatr Serv. 2019;70:1082-7.

108 Runeson B, Odeberg J, Pettersson A, Edbom T, Jildevik Adamsson $\mathrm{IJ}$, Waern M. Instruments for the assessment of suicide risk: a systematic review evaluating the certainty of the evidence. PLoS One. 2017;12:e0180292. 